\title{
Transducin $\beta$-Subunit Can Interact with Multiple G-Protein $\gamma$-Subunits to Enable Light Detection by Rod Photoreceptors
}

\author{
Paige M. Dexter, ${ }^{1}$ Ekaterina S. Lobanova, ${ }^{2}$ Stella Finkelstein, ${ }^{2}$ William J. Spencer, ${ }^{1}$ (D) Nikolai P. Skiba, ${ }^{2}$ \\ and ${ }^{-V}$ Vadim Y. Arshavsky ${ }^{1,2}$
}

DOI:http://dx.doi.org/10.1523/ENEURO.0144-18.2018

${ }^{1}$ Department of Pharmacology and Cancer Biology, Duke University School of Medicine, Durham, North Carolina 27710 and ${ }^{2}$ Albert Eye Research Institute, Duke University, Durham, North Carolina 27710

\section{Visual Overview}

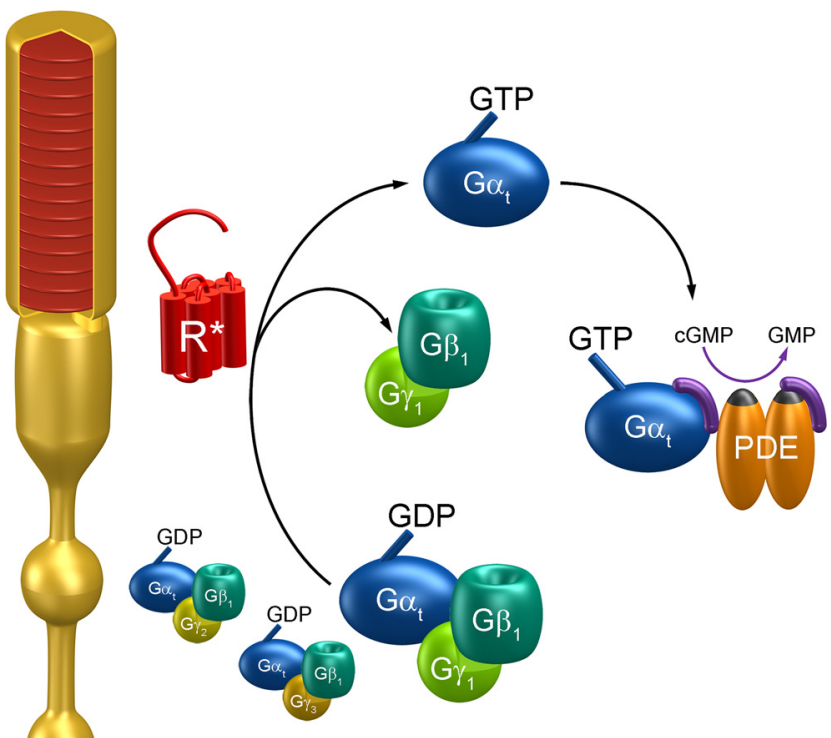

The heterotrimeric G-protein transducin mediates visual signaling in vertebrate photoreceptor cells. Many aspects of the function of transducin were learned from knock-out mice lacking its individual subunits. Of particular interest is the knockout of its rod-specific $\gamma$-subunit $\left(\mathrm{G} \gamma_{1}\right)$. Two studies using independently generated mice documented that this knockout results in a considerable $>60$-fold reduction in the light sensitivity of affected rods, but provided different interpretations of how the remaining $\alpha$-subunit $\left(\mathrm{G} \alpha_{\mathrm{t}}\right)$ mediates phototransduction without its cognate $\mathrm{G} \beta_{1} \gamma_{1}$ subunit partner. One study found that the light sensitivity reduction matched a corresponding reduction in $\mathrm{G} \alpha_{\mathrm{t}}$ content in the light-sensing rod outer segments and proposed that $\mathrm{G} \alpha_{\mathrm{t}}$ activation is supported by remaining $\mathrm{G} \beta_{1}$ associating with other $\mathrm{G} \gamma$ subunits naturally expressed in photoreceptors. In contrast, the second study reported the same light sensitivity loss but a much lower, only approximately sixfold, reduction of $\mathrm{G} \alpha_{\mathrm{t}}$ and proposed that the light responses of these rods do not require $\mathrm{G} \beta \gamma$ at all. To resolve this controversy and elucidate the mechanism driving visual signaling in $\mathrm{G} \gamma_{1}$ knock-out rods, we analyzed both mouse lines side by side. We first determined that the outer segments of both mice have identical $\mathrm{G} \alpha_{\mathrm{t}}$ content, which is reduced $\sim 65$-fold from the wild-type (WT) level. We further demonstrated that the remaining $\mathrm{G} \beta_{1}$ is present in a complex with endogenous $\mathrm{G} \gamma_{2}$ and $\mathrm{G} \gamma_{3}$ subunits and that these complexes exist in wild-type rods as well. Together, these results argue against the idea

\section{Significance Statement}

Phototransduction has been a valuable system for understanding the basic principles of G-protein signaling. One question that has remained unanswered is whether the G-protein $\alpha$-subunit can support signaling without its cognate $\beta \gamma$ partner complex. Previous studies investigating this question in photoreceptors of $\mathrm{G} \gamma_{1}$ knock-out mice came to mutually exclusive conclusions. We now resolve this controversy by showing that phototransduction in this knockout is supported by alternative $\beta \gamma$ complexes rather than the $\alpha$-subunit alone. Most importantly, this study highlights the functional interchangeability of different $\gamma$-subunits in the context of an intact in vivo system. 
that $\mathrm{G} \alpha_{\mathrm{t}}$ alone supports light responses of $\mathrm{G} \gamma_{1}$ knock-out rods and suggest that $\mathrm{G} \beta_{1} \gamma_{1}$ is not unique in its ability to mediate vertebrate phototransduction.

Key words: G-protein; phototransduction; retinal degeneration; transducin

\section{Introduction}

The heterotrimeric G-protein transducin mediates visual signal transduction in the outer segments of vertebrate photoreceptor cells. The visual signal, or photoresponse, is initiated when photoexcited rhodopsin activates the transducin heterotrimer by catalyzing GDP-GTP exchange on its $\alpha$-subunit $\left(\mathrm{G} \alpha_{\mathrm{t}}\right)$. $\mathrm{G} \alpha_{\mathrm{t}}$ subsequently dissociates from the $\beta \gamma$-subunit complex (consisting of $\mathrm{G} \beta_{1}$ and $\mathrm{G} \gamma_{1}$ ) to stimulate the downstream effector type 6 cGMP phosphodiesterase. The resulting reduction in cytosolic cGMP causes cGMP-gated ion channel closure, photoreceptor hyperpolarization, and decreased glutamate release from the synaptic terminal (for review, see Arshavsky and Burns, 2012). This signal is processed further by downstream retinal neurons before being transmitted to the brain.

Previous studies have demonstrated that knocking out individual transducin subunits produces quite different phenotypes. For example, the rods of $\mathrm{G} \alpha_{\mathrm{t}}$ knock-out mice are completely insensitive to light (Calvert et al., 2000), while $\mathrm{G} \gamma_{1}$ knock-out rods retain distinct light sensitivity despite the absence of this critical component of the transducin heterotrimer (Lobanova et al., 2008; Kolesnikov et al., 2011). Next, the absence of $\mathrm{G} \alpha_{\mathrm{t}}$ does not affect the expression levels of its cognate $\mathrm{G} \beta_{1} \gamma_{1}$ complex (Calvert et al., 2000; Lobanova et al., 2008), whereas the expression levels of both $\mathrm{G} \alpha_{\mathrm{t}}$ and $\mathrm{G} \beta_{1}$ are drastically reduced in the $\mathrm{G} \gamma_{1}$ knockout (Lobanova et al., 2008; Kolesnikov et al., 2011). Finally, the knockout of $\mathrm{G} \alpha_{\mathrm{t}}$ does not affect photoreceptor viability (Calvert et al., 2000), whereas $\mathrm{G} \gamma_{1}$ knock-out mice undergo progressive photoreceptor degeneration (Lobanova et al., 2008; Kolesnikov et al., 2011). The latter originates from proteostatic stress arising from the requirement to degrade vast

Received April 10, 2018; revised May 7, 2018; accepted May 10, 2018; First published May 17, 2018.

${ }^{1}$ The authors declare no competing financial interests.

${ }^{2}$ Author contributions: P.M.D., E.S.L., and V.Y.A. designed research; P.M.D., E.S.L., S.F., W.J.S., and N.P.S. performed research; P.M.D., E.S.L., S.F., W.J.S., N.P.S., and V.Y.A. analyzed data; P.M.D. and V.Y.A. wrote the paper.

${ }^{3}$ This study was supported by the National Institutes of Health Grants EY-022959 (V.Y.A.), EY-05722 (V.Y.A.), EY-026468 (P.M.D.), and EY-025558 (W.J.S.); and the Unrestricted Award from Research to Prevent Blindness, Inc. to Duke University.

Acknowledgments: We thank Dr. O.G. Kisselev for providing the StL G $\gamma_{1}$ knock-out mouse and $\mathrm{Y}$. Hao for preparing the plastic-embedded retinal cross sections.

Correspondence should be addressed to Vadim Y. Arshavsky, Duke University Eye Center, 5012 AERI, 2351 Erwin Road, Durham, NC 27710. E-mail: vadim.arshavsky@duke.edu.

E.S. Lobanova's present address: Department of Ophthalmology, University of Florida, Gainesville, FL 32610.

DOI:http://dx.doi.org/10.1523/ENEURO.0144-18.2018

Copyright (C) 2018 Dexter et al.

This is an open-access article distributed under the terms of the Creative Commons Attribution 4.0 International license, which permits unrestricted use, distribution and reproduction in any medium provided that the original work is properly attributed. amounts of $\mathrm{G} \beta_{1}$, unable to fold without its $\mathrm{G} \gamma_{1}$ partner (Lobanova et al., 2013).

In a previous attempt to understand the nature of light responses in $\mathrm{G \gamma}_{1}^{-1-}$ rods, the reduction in transducin subunits in their outer segments was correlated with the reduction in their light sensitivity (Lobanova et al., 2008). $\mathrm{G} \gamma_{1}^{-1-}$ outer segments were shown to contain $\sim 50$-fold less $\mathrm{G} \alpha_{\mathrm{t}}$ and $\mathrm{G} \beta_{1}$ than WT rods, a reduction very close to the $\sim 67$-fold loss in their light sensitivity also reported in that study. Because photoreceptor light sensitivity is directly proportional to the rate of transducin activation, which in turn is proportional to its concentration on outer segment discs (Pugh and Lamb, 1993; Heck and Hofmann, 2001; Sokolov et al., 2002; Arshavsky and Burns, 2014), it was suggested that $G \gamma_{1}^{-1-}$ light responses are conveyed by transducin heterotrimer using an alternate G-protein $\gamma$-subunit to enable its efficient activation by rhodopsin. However, attempts to identify this replacement $\mathrm{G} \gamma$ were unsuccessful due to the low transducin content in these retinas.

More recently, an alternative $G \gamma_{1}^{-1-}$ mouse with a transgenic design different from that used by Lobanova et al. (2008) was characterized by Kolesnikov et al. (2011). Notably, rod photoresponses recorded from these mice had characteristics very similar to those described by the first study, including a 90-fold reduction in light sensitivity from the WT level. However, the outer segment content of $\mathrm{G} \alpha_{\mathrm{t}}$ was estimated to be only sixfold lower than normal. Based on previously published evidence that rhodopsin can activate $\mathrm{G} \alpha_{\mathrm{t}}$ in vitro without $\mathrm{G} \beta_{1} \gamma_{1}$, although significantly slower than normally (Fung, 1983; Kisselev et al., 1999; Herrmann et al., 2006), the authors argued that $\mathrm{G} \gamma_{1}^{-1-}$ rod photoresponses are conveyed by $\mathrm{G} \alpha_{\mathrm{t}}$ acting alone. They also described a slower progression of photoreceptor degeneration in $\mathrm{G} \gamma_{1}^{-1-}$ retinas than observed by Lobanova et al. (2008), which was attributed to differences in the genetic backgrounds of these strains.

To settle these discrepancies and elucidate the mechanism driving visual signaling in $G \gamma_{1}^{-1-}$ rods, we performed a side-by-side analysis of both $G \gamma_{1}^{-1-}$ mouse strains. First, we compared the amounts of $\mathrm{G} \alpha_{\mathrm{t}}$ and $\mathrm{G} \beta_{1}$ in retinal lysates of these strains and found that the decrease in expression levels of both subunits was identical and corresponded to the decrease initially reported by Lobanova et al. (2008). Most importantly, this decrease was comparable to the decrease in rod photoresponse sensitivity reported for both strains. We next demonstrated that the remaining $\mathrm{G} \beta_{1}$ is present in a complex with endogenous $\mathrm{G} \gamma_{2}$ and $\mathrm{G} \gamma_{3}$ subunits. These results indicate that $\mathrm{G} \beta_{1} \gamma_{1}$ is not the sole $\mathrm{G} \beta \gamma$ complex able to facilitate phototransduction and that $\mathrm{G} \beta_{1}$ associated with alternative, noncanonical $\mathrm{G} \gamma$ subunits supports transducin activation in $G \gamma_{1}^{-1-}$ rods at an efficiency comparable to that of the canonical $\mathrm{G} \beta_{1} \gamma_{1}$ complex.

Given the significant difference reported in the progression of photoreceptor degeneration for the two $G \gamma_{1}^{-1-}$ 
strains, we also performed a systematic analysis of retinal degeneration in these animals. We have found that photoreceptors of these mice degenerate at nearly the same rate, and both strains display phenotypes consistent with abnormal proteostasis in their rods.

\section{Materials and Methods}

\section{Animals}

Mouse care and experiments were performed in accordance with procedures approved by the Institutional Animal Care and Use Committee of Duke University. The Deltagen $\mathrm{G} \gamma_{1}$ knockout was licensed from Deltagen Inc. (San Mateo, CA) (Target ID 408) and was previously characterized in the study by Lobanova et al. $(2008,2013)$. In this mouse, regions of the $\mathrm{G} \gamma_{1}$ coding sequence (amino acids 17-44 and intron 2) were replaced with a $6.9 \mathrm{~kb}$ IRES-lacZ reporter and neomycin resistance cassette. The StL $\mathrm{G} \gamma_{1}$ knockout, previously characterized in the study by Kolesnikov et al. (2011), was provided by Dr. O.G. Kisselev (Saint Louis University, St. Louis, MO). In this mouse, the targeting construct replaced all three exons with a Neo cassette to eliminate the coding region of $\mathrm{G} \gamma_{1}$. Transgenic mice heterozygously expressing the $\mathrm{Ub}^{\mathrm{G} 76 \mathrm{~V}}$-GFP reporter are described in the study by Lindsten et al. (2003). WT mice used in this study were C57BL/6J from The Jackson Laboratory. None of the mouse lines contained the Rd8 mutation. Mice of either sex were used for all experiments.

\section{Antibodies}

Rabbit anti-G $\alpha_{\mathrm{t}}$ (sc-389), anti-G $\beta_{1}$ (sc-379), anti-G $\gamma_{2}$ (sc-374), and anti-G $\gamma_{3}$ (sc-375) antibodies, and mouse anti-G $\gamma_{2}$ (sc-134344) and anti- $\beta$-actin (sc-47778) antibodies were from Santa Cruz Biotechnology. Rabbit antiPSMD1 (ab140682) antibody was from Abcam. Rabbit anti-G $\beta_{1}$ (GTX114442) was from GeneTex. The specificity of the anti-G $\alpha_{\mathrm{t}}$ antibody in the context of retinal tissue was directly tested in $\mathrm{G} \alpha_{\mathrm{t}}$ knock-out animals. The specificity of other antibodies was assumed per manufacturer descriptions. Secondary goat or donkey antibodies for Western blotting conjugated with Alexa Fluor 680 and 800 were from Invitrogen. Protein bands were visualized and quantified using the Odyssey Infrared Imaging System (LI-COR Biosciences).

\section{Western blotting}

For quantitative Western blot analysis of $\mathrm{G} \alpha_{\mathrm{t}}$ and $\mathrm{G} \beta_{1}$ protein levels, two mouse retinas per sample were solubilized in $150 \mu \mathrm{l}$ of $1 \%$ Triton X-100 in PBS. Total protein concentration was measured using the DC Protein Assay kit (Bio-Rad), and samples were diluted with SDS-PAGE sample buffer to achieve a protein concentration of 1 $\mu \mathrm{g} / \mu \mathrm{l}$. Aliquots from $\mathrm{G} \gamma_{1}$ knock-out mice containing 10 $\mu \mathrm{g}$ of total protein were separated by SDS-PAGE along with a serial dilution of WT retinal lysate.

\section{Histology and microscopy}

Agarose-embedded retinal cross sections were prepared as previously described (Lobanova et al., 2010), collected in 24-well plates, and incubated for $2 \mathrm{~h}$ with Alexa Fluor 594 conjugate of wheat germ agglutinin (In- vitrogen) in PBS containing $0.1 \%$ Triton $\mathrm{X}-100$. Sections were washed three times in PBS, mounted with Fluoromount $\mathrm{G}$ (Electron Microscopy Sciences) under glass coverslips, and visualized using a Nikon Eclipse 90i Confocal Microscope.

Plastic-embedded retinal cross sections ( $1 \mu \mathrm{m}$ thick) were prepared as previously described (Sokolov et al., 2004) and stained with toluidine blue for light microscopy. Tiled images of whole retina cross sections were obtained using the Olympus IX-81 Inverted Fluorescence Microscope, and aligned and stitched using the Olympus cellSens Dimension software. The number of photoreceptor nuclei in representative segments of outer nuclear layer (ONL) was quantified as a quantitative measure of surviving photoreceptors. The number of nuclei in a 400 $\mu \mathrm{m}$ segment of the ONL, located at $1 \mathrm{~mm}$ from each side of the optic nerve, was counted by hand.

\section{Rod outer segment isolation}

Rod outer segments were isolated from WT and $G \gamma_{1}^{-1-}$ retinas as previously described (Tsang et al., 1998), with minor modifications. Briefly, retinas from 6-10 animals were removed from the eyecups and placed in $150 \mu \mathrm{l}$ of 8\% OptiPrep Density Gradient Medium (Sigma-Aldrich) in mouse Ringer's buffer (130 mM NaCl, 3.6 mM KCl, $2.4 \mathrm{~mm}$ $\mathrm{MgCl}_{2}, 1.2 \mathrm{~mm} \mathrm{CaCl} 2,10 \mathrm{~mm}$ HEPES, and $0.02 \mathrm{~mm}$ EDTA, $\mathrm{pH}$ 7.4). The tubes were vortexed at maximum speed for $60 \mathrm{~s}$ and centrifuged at $200 \times g$ for $60 \mathrm{~s}$, and the supernatant containing rod outer segments was gently collected. Two hundred microliters of fresh 8\% OptiPrep solution was added to the retinal pellet, and vortexing/ sedimentation was performed again. This sequence was repeated at least five times. The combined supernatant was loaded on a step gradient made with $10 \%$ and $18 \%$ OptiPrep in a $4 \mathrm{ml}$ centrifuge tube and centrifuged in a swing-bucket rotor at $115,000 \times g$ for $30 \mathrm{~min}$. Rod outer segments were collected from the interface between $10 \%$ and $18 \%$ OptiPrep, diluted with $4 \mathrm{ml}$ of Ringer's solution, and centrifuged at $100,000 \times g$ for $1 \mathrm{~h}$. The pellet containing rod outer segments was rinsed once with $200 \mu \mathrm{l}$ of Ringer's solution, resuspended in $200 \mu$ l of PBS, snap frozen in liquid $\mathrm{N}_{2}$, and stored at $-80^{\circ} \mathrm{C}$ until use.

\section{Immunoprecipitation}

Samples were prepared for immunoprecipitation as previously described (Pearring et al., 2015). Briefly, purified rod outer segments were thawed and their protein content was determined using the DC Protein Assay Kit. Samples were diluted to $0.5 \mu \mathrm{g} / \mu \mathrm{l}$ protein in the immunoprecipitation buffer $(0.1 \% n$-dodecyl- $\beta$-maltoside in PBS with protease inhibitor cocktail, Sigma-Aldrich), vortexed, and centrifuged at $108,000 \times g$ for $30 \mathrm{~min}$. The supernatant was removed for use in immunoprecipitation. Protein A Mag Sepharose beads (catalog \#28944006, GE Healthcare Life Sciences) and Protein G Mag Sepharose Xtra beads (catalog \#28967066, GE Healthcare Life Sciences) were used for immunoprecipitation with rabbit and mouse antibodies, respectively. In both cases, $5 \mu \mathrm{l}$ beads were incubated with $5 \mu \mathrm{g}$ of antibody for $2 \mathrm{~h}$ under rotation at room temperature. The beads were rinsed and incubated with $12.5 \mu \mathrm{g}$ of rod outer segment lysate over- 


\begin{tabular}{|c|c|c|c|c|}
\hline Line & Figure/table & Data distribution & Type of test & $\overline{p \text { value }}$ \\
\hline a & $\begin{array}{l}\text { Fig. } 1 \mathrm{C} \\
\text { All data }\end{array}$ & $N$ too small to determine if normally distributed & N/A & N/A \\
\hline $\mathrm{b}$ & $\begin{array}{l}\text { Table } 2 \\
\text { All data }\end{array}$ & $N$ too small to determine if normally distributed & Confidence score from Scaffold 4.8 & $\mathrm{~N} / \mathrm{A}$ \\
\hline c & $\begin{array}{l}\text { Fig. 3B } \\
\text { Deltagen vs StL at } 1 \text { month }\end{array}$ & $N$ too small to determine if normally distributed & Mann-Whitney $U$ test & 0.065 \\
\hline d & $\begin{array}{l}\text { Fig. 3B } \\
\text { Deltagen vs StL at } 3 \text { months }\end{array}$ & $N$ too small to determine if normally distributed & Mann-Whitney $U$ test & 0.041 \\
\hline e & $\begin{array}{l}\text { Fig. 3B } \\
\text { Deltagen vs StL at } 6 \text { months }\end{array}$ & $N$ too small to determine if normally distributed & Mann-Whitney $U$ test & 0.24 \\
\hline
\end{tabular}

night under rotation at $4^{\circ} \mathrm{C}$. After the beads were rinsed, bound proteins were eluted by boiling in the SDS-PAGE loading buffer (2\% SDS) at $95^{\circ} \mathrm{C}$ for $10 \mathrm{~min}$ and analyzed by Western blotting.

\section{Mass spectrometry}

Peptide mixes obtained from in-gel tryptic digests were analyzed using a nanoACQUITY UPLC System coupled to a Synapt G2 Mass Spectrometer (Waters). Peptides were separated on a $75 \mu \mathrm{m} \times 150 \mathrm{~mm}$ column with $1.7 \mu \mathrm{m} \mathrm{C18}$ BEH (Ethylene Bridged Hybrid) particles (Waters) using a 90 min gradient of $6-32 \%$ acetonitrile with $0.1 \%$ formic acid at a flow rate of $0.3 \mu \mathrm{l} / \mathrm{min}$ at $35^{\circ} \mathrm{C}$. For each sample, we conducted data-dependent analysis (DDA) using a 0.8 $\mathrm{s}$ mass spectrometry (MS) scan followed by tandem MS (MS/MS) acquisition on the top three ions. MS/MS scans for each ion used an isolation window of $\sim 3 \mathrm{Da}$ and a dynamic exclusion window of $90 \mathrm{~s}$ within $1.2 \mathrm{Da}$. DDA data were converted to searchable files using ProteinLynx Global Server 2.5.1 (Waters) and searched against the Uniprot mouse database using Mascot Server version 2.5 with the following parameters: maximum one missed cleavage site, carbamidomethylation at Cys residues as fixed modification and Met oxidation, Asn, Gln deamidation, and protein $N$-acetylation as variable modifications. Precursor ion mass tolerance was set to 20 ppm, and fragment mass tolerance was set to $0.25 \mathrm{Da}$.

\section{Statistical analysis}

For quantification of rod outer segment content of $\mathrm{G} \alpha_{\mathrm{t}}$ and $\mathrm{G} \beta_{1}$ subunits and comparative analysis of retinal morphology, data are presented as the mean \pm SD. All statistical analyses were performed with GraphPad Prism 7.04. Morphologic data were analyzed using the nonparametric Mann-Whitney $U$ test, and results were considered statistically significant at $p<0.05$. For the MS identification of G-protein $\gamma$-subunits present in rod outer segments, Mascot data were imported into Scaffold 4.8 (Proteome Software) to merge all of the data for a sample represented by multiple gel bands, to estimate a confidence score for protein identification, and to perform a relative protein quantification based on the sum of intensities of the constituent peptides.

\section{Results}

Hereafter, we will refer to the two $G \gamma_{1}^{-1-}$ mouse strains analyzed in this study as "Deltagen" and "StL" $G \gamma_{1}^{-/-}$ mice, as the mouse described in the study by Lobanova et al. (2008) was produced by and licensed from Deltagen and the mouse characterized in the study by Kolesnikov et al. (2011) was produced at Saint Louis University.

\section{Identification of transducin $\alpha$ - and $\beta$-subunit levels in $G \gamma_{1}^{-/-}$retinal lysates}

We used quantitative Western blotting to directly compare the levels of $\mathrm{G} \alpha_{\mathrm{t}}$ and $\mathrm{G} \beta_{1}$ in the two $\mathrm{G} \gamma_{1}$ knock-out models. Retinas were harvested at 1 month of age and lysed, and proteins from the lysates were separated by SDS-PAGE alongside serial dilutions of retinal lysates from WT mice (Fig. 1A). G $\alpha_{\mathrm{t}}$ and $\mathrm{G} \beta_{1}$ were then detected by immunoblotting with specific antibodies against each protein. The standard curves relating band intensity to total protein amount were obtained from WT lysates and used to calculate relative contents of $\mathrm{G} \alpha_{\mathrm{t}}$ and $\mathrm{G} \beta_{1}$ in each model (Fig. 1B).

This analysis revealed an identical reduction in the contents of transducin subunits in the retinas of both mouse strains (Fig. 1C). $\mathrm{G} \alpha_{\mathrm{t}}$ was present at $3.3 \%$ and $3.0 \%$ of the WT amount in Deltagen and StL retinas, respectively, whereas $\mathrm{G} \beta_{1}$ was present at $6.9 \%$ and $7.1 \%$ of the WT amount. $^{a}$ These numbers are very close to those previously reported for the Deltagen mouse (3.9\% remaining $\mathrm{G} \alpha_{\mathrm{t}}$ and $10.6 \% \mathrm{G} \beta_{1}$; Lobanova et al., 2008), a conclusion reinforced by the fact that the standard curves in the study by Lobanova et al. (2008) were generated based on an alternative methodology using purified protein standards rather than serial dilutions of WT retinal extracts. It is worth noting that the difference between the conclusions of the two studies could not be attributed to different states of light-dependent transducin translocation, a phenomenon taking place in WT rods (Sokolov et al., 2002), because transducin does not translocate in $G \gamma_{1}^{-1-}$ rods (Lobanova et al., 2008). These data clearly demonstrate that the amount of transducin remaining in retinas of the StL mouse was overestimated and that this aspect of the $\mathrm{G} \gamma_{1}^{-1-}$ phenotype is strain independent.

We next calculated how much $\mathrm{G} \alpha_{\mathrm{t}}$ and $\mathrm{G} \beta_{1}$ is present in rod outer segments of $\mathrm{G} \gamma_{1}^{-1-}$ mice, taking into account that approximately one-half of each subunit is mislocalized from $G \gamma_{1}^{-1-}$ rod outer segments and a large ( $82 \%$ ) fraction of $G \beta_{1}$ in this mouse is expressed in the inner retina (Lobanova et al., 2008; Table 1). Therefore, rod outer segments of Deltagen $\mathrm{G} \gamma_{1}^{-1-}$ mice contain between $\sim 1.5 \%$ (based on the lower value of $3.0 \%$ measured in 
A

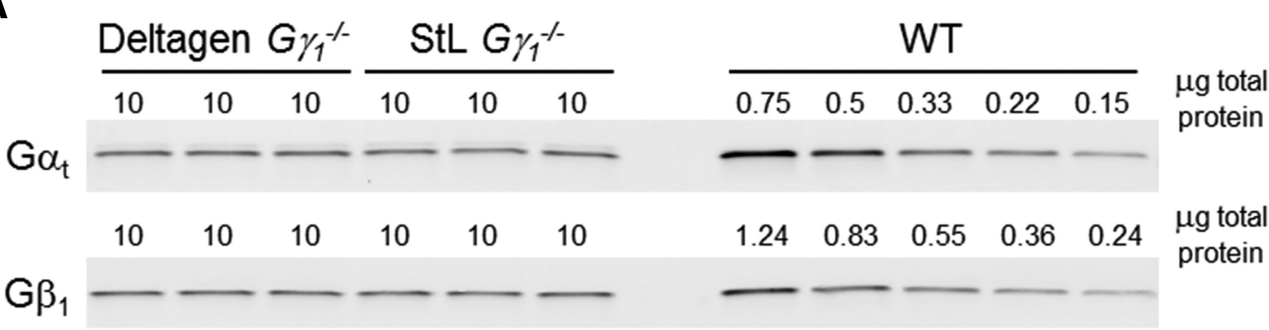

B
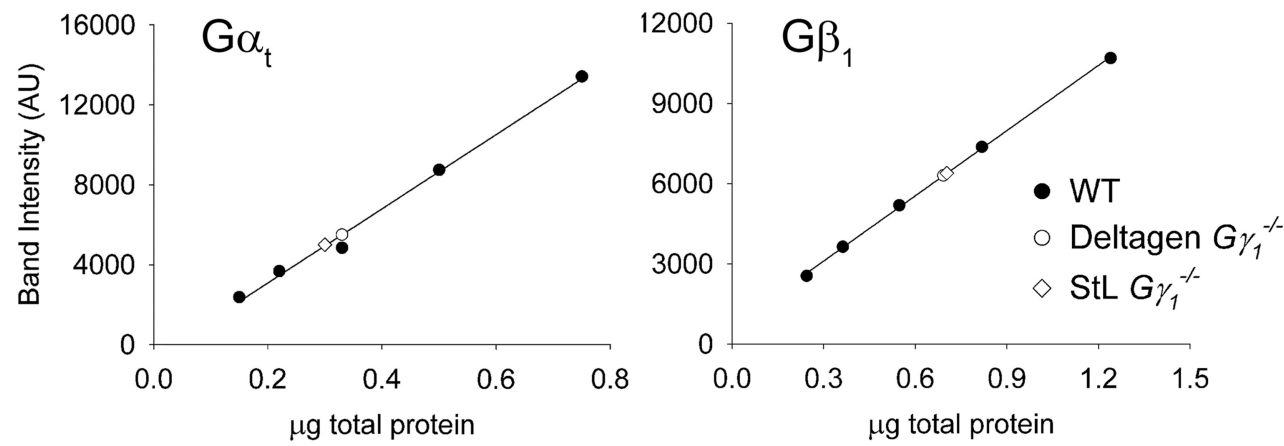

C

The amounts of $G_{t}$ subunits in $G \gamma_{1}^{-/}$retinas expressed as percentages of their WT amounts

\begin{tabular}{lcc}
\hline & $G \alpha_{t}$ & $G \beta_{1}$ \\
\hline Deltagen $G \gamma_{1}^{-1}$ & $3.3 \pm 0.1$ & $6.9 \pm 0.2$ \\
StL $G \gamma_{1}^{--}$ & $3.0 \pm 0.3$ & $7.1 \pm 0.7$ \\
\hline
\end{tabular}

Figure 1. Comparative analysis of $\mathrm{G} \alpha_{\mathrm{t}}$ and $\mathrm{G} \beta_{1}$ expression levels in retinal lysates from 1-month-old $\mathrm{G} \gamma_{1}^{-1-}$ mice. $\boldsymbol{A}$, Retinal lysates from Deltagen and StL mouse strains containing $10 \mu \mathrm{g}$ of total protein were separated by SDS-PAGE alongside serial dilutions of WT retinal lysates and were immunoblotted with antibodies against each transducin subunit. Data are taken from one of three similar experiments. $\boldsymbol{B}$, The relative contents of $\mathrm{G} \alpha_{\mathrm{t}}$ and $\mathrm{G} \beta_{1}$ in retinal lysates analyzed in $\boldsymbol{A}$ were determined from the calibration curves obtained from the WT lysate dilutions ( $\mathrm{G} \alpha_{\mathrm{t}}$ regression equation: $y=18,600 \times x-623 ; \mathrm{G} \beta_{1}$ regression equation: $y=8130 \times x+665$ ). - =WT, $\bigcirc=$ Deltagen $G \gamma_{1}^{-1-}$, and $\diamond=$ StL $G \gamma_{1}^{-1-}$. C. The amounts of transducin subunits in $G \gamma_{1}^{-1-}$ retinas averaged across three independent experiments are expressed as percentages of their amounts in WT retinas (mean \pm SD). The amount of G $\beta_{1}$ was corrected to reflect that only $18 \%$ of $\mathrm{G} \beta_{1}$ in $\mathrm{G} \gamma_{1}^{-1-}$ retinas is expressed in rods, whereas the rest is expressed in the inner retina (Lobanova et al., 2008).

Fig. 1) and $\sim 2 \%$ (based on the higher $3.9 \%$ value measured in the study by Lobanova et al., 2008) of WT G $\alpha_{\mathrm{t}}$. The range for the $\mathrm{G} \beta_{1}$ amount in $\mathrm{G} \gamma_{1}^{-1-}$ outer segments is between $0.6 \%$ and $1 \%$ of its WT content (based on the

Table 1. The amounts of transducin subunits in $\mathrm{G} \gamma_{1}^{-1-}$ rod outer segments and the corresponding sensitivities of rod light responses expressed as percentages of WT

\begin{tabular}{llll}
\hline & $\mathrm{G} \alpha_{\mathrm{t}}$ & $\mathrm{G} \beta_{1}$ & Light sensitivity \\
Deltagen $\mathrm{G} \gamma_{1}{ }^{-1-}$ & $1.5-2.0 \%$ & $0.6-1.0 \%$ & $1.5 \%$ \\
StL $\mathrm{G} \gamma_{1}{ }^{-/-}$ & $1.5 \%$ & $0.7 \%$ & $1.1 \%$
\end{tabular}

The mean values for protein content in retinas were taken from Fig. 1 and the study by Lobanova et al. (2008) and were corrected for the outer segment fraction of each protein, as described in the text. Relative light sensitivities were derived from the single-cell recordings in the studies by Lobanova et al. (2008) and Kolesnikov et al. (2011) by dividing the value of half-saturating light intensity of WT rods by the corresponding value for $\mathrm{G} \gamma_{1}^{-1-}$ rods. total retinal amounts of $7 \%$ and $10.6 \%$, respectively, obtained in the current and previous study). The corresponding amounts for the StL mice derived from the values reported in Fig. 1 are $1.5 \%$ and $0.7 \%$ of WT, respectively, for $\mathrm{G} \alpha_{\mathrm{t}}$ and $\mathrm{G} \beta_{1}$ (Table 1).

\section{Consideration of transducin activation mechanism in $\mathrm{G} \gamma_{1}^{-1-}$ rods}

Precise determination of the degree of transducin subunit loss in the outer segments of $G \gamma_{1}^{-1-}$ rods allows critical evaluation of the two hypotheses explaining light signaling in these cells: $\mathrm{G} \alpha_{\mathrm{t}}$ activated alone versus $\mathrm{G} \alpha_{\mathrm{t}}$ activation assisted by an alternative $\mathrm{G} \beta \gamma$. As mentioned above, the reduction in photoresponse sensitivity documented for these cells was consistent between both studies ( 67 -fold in Lobanova et al., 2008; 90-fold in Kolesnikov et al., 2011). This represents $1.1-1.5 \%$ of WT 
Table 2. Mass spectrometry identification of G-protein $\gamma$-subunits present in rod outer segments of WT and $G \gamma_{1}^{-1-}$ mice

\begin{tabular}{clll}
\hline WT & Peptides $(n)$ & Protein score & Confidence score \\
$\mathrm{G} \gamma_{1}$ & 6 & 187 & \\
$\mathrm{G} \gamma_{2}$ & 1 & 26 & 100 \\
$\mathrm{G} \gamma_{3}$ & 2 & 23 & 99.2 \\
$\mathrm{G} \gamma_{1}^{-/-}$ & & & 31 \\
$\mathrm{G} \gamma_{2}$ & 2 & 25 & \\
$\mathrm{G} \gamma_{3}$ & 1 & 55 & 99.9 \\
\hline
\end{tabular}

sensitivity and is very close to the degree of $\mathrm{G} \alpha_{\mathrm{t}}$ and $\mathrm{G} \beta_{1}$ reduction determined in the previous section (Table 1). Because photoreceptor light sensitivity is directly proportional to the concentration of transducin heterotrimer on the membranes of outer segment discs (Pugh and Lamb, 1993; Heck and Hofmann, 2001; Sokolov et al., 2002; Arshavsky and Burns, 2014), the comparable reduction in $\mathrm{G} \alpha_{\mathrm{t}}$ and photoresponse sensitivity indicates that the $\mathrm{G} \alpha_{\mathrm{t}}$ remaining in $G \gamma_{1}^{-1-}$ rod outer segments is activated by rhodopsin at nearly the same efficiency as in WT outer segments. On the other hand, the efficiency of $\mathrm{G} \alpha_{\mathrm{t}}$ activation by rhodopsin without $\mathrm{G} \beta \gamma$ is at least an order of magnitude lower than with $\mathrm{G} \beta \gamma$ (Fung, 1983; Kisselev et al., 1999; Herrmann et al., 2006). This argues that $\mathrm{G} \alpha_{\mathrm{t}}$ activation in $G \gamma_{1}^{-1-}$ rods is supported by a complex between $\mathrm{G} \beta_{1}$ and a G-protein $\gamma$-subunit replacing $\mathrm{G} \gamma_{1}$ in these rods. We therefore set up a search for this alternative $\mathrm{G} \beta_{1} \gamma$ complex in $\mathrm{G} \gamma_{1}^{-1-}$ rods.

\section{Identification of alternative $\mathrm{G} \beta \gamma$ complexes in $\mathrm{G} \gamma_{1}^{-1-}$ and WT rod outer segments}

To elucidate the molecular composition of the putative $\mathrm{G} \beta_{1} \gamma$ complexes supporting visual function in the absence of $\mathrm{G} \gamma_{1}$, we first conducted MS identification of all G-protein $\gamma$-subunits present in rod outer segments of WT and $G \gamma_{1}^{-1-}$ mice. Outer segments were purified from each mouse type, and their proteins were separated by SDSPAGE. Gel fragments containing G-protein $\gamma$-subunits were excised, and proteins were subjected to in-gel tryptic digestion followed by liquid chromatography-MS/MS analysis of the resulting peptides. Of the 14 G-protein $\gamma$-subunits encoded in the mouse genome (Milligan and Kostenis, 2006), only 3 were found in WT and 2 were found in $G \gamma_{1}^{-1-}$ outer segments (Table 2). As expected, WT but not $G \gamma_{1}^{-1-}$ outer segments contained $G \gamma_{1}$. The other two subunits, $G \gamma_{2}$ and $G \gamma_{3}$, were found in both preparations, although the confidence score for $\mathrm{G} \gamma_{3}$ in the WT preparation was low. ${ }^{\mathrm{b}}$ A rough estimate, based on comparing the total ion intensity produced by all peptides representing each $\mathrm{G} \gamma$ subunit type, suggested that for every 82 molecules of $\mathrm{G} \gamma_{1}$ present in WT outer segments there are 3 molecules of $\mathrm{G} \gamma_{2}$ and 1 molecule of $\mathrm{G} \gamma_{3}$. A similar estimate performed for $G \gamma_{1}^{-1-}$ rod outer segments suggested a molar ratio of $\sim 1.7$ between $\mathrm{G} \gamma_{2}$ and $\mathrm{G} \gamma_{3}$. These results narrowed the list of potential $\mathrm{G} \beta_{1}$ binding partners in $G \gamma_{1}^{-1-}$ outer segments to these two $\gamma$-subunits.

Therefore, we sought to directly demonstrate that $\mathrm{G} \beta_{1}$ forms complexes with $\mathrm{G} \gamma_{2}$ and/or $\mathrm{G} \gamma_{3}$ in $G \gamma_{1}^{-1-}$ rod outer segments by coimmunoprecipitating these putative complexes using antibodies against $\mathrm{G} \gamma_{2}$ and $\mathrm{G} \gamma_{3}$. We have found that a significant fraction of $\mathrm{G} \beta_{1}$ in $G \gamma_{1}^{-1-}$ rod outer segments was precipitated with antibodies specifically recognizing $\mathrm{G} \gamma_{2}$ or $\mathrm{G} \gamma_{3}$ (Fig. $2 A, B$ ). These results confirm that $G \beta_{1}$ remaining in the rod outer segments of $G \gamma_{1}^{-1-}$ mice indeed forms complexes with both of these $\gamma$-subunits. We also attempted to conduct a reciprocal coprecipitation experiment, but unfortunately were not able to identify a precipitating antibody against $\mathrm{G} \beta_{1}$.

We next sought to determine whether these alternative $\mathrm{G} \beta \gamma$ complexes only form in the absence of $\mathrm{G} \gamma_{1}$ or whether they are also present in WT rods. To test this, we repeated coimmunoprecipitation experiments using rod outer segments from WT mice (Fig. 2C,D). This analysis

\section{G $\gamma_{1}^{-/}$outer segments}

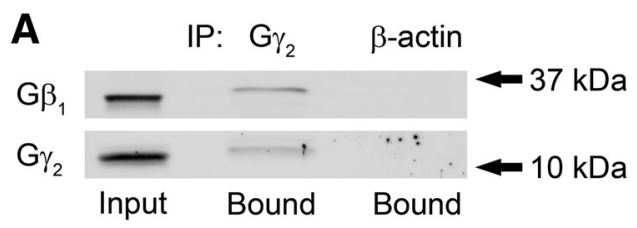

\section{WT outer segments}
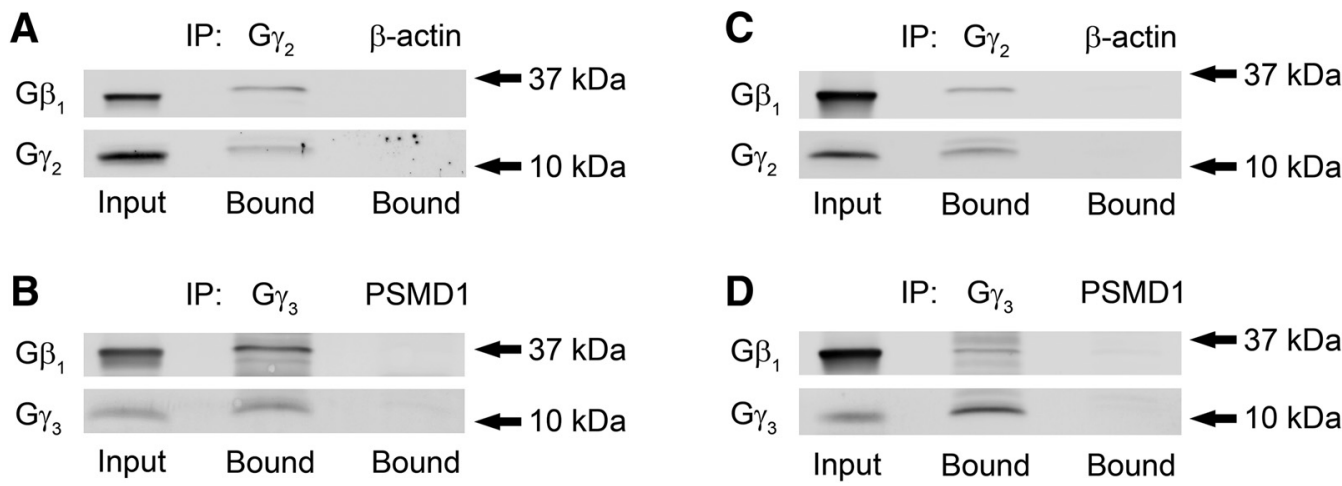

Figure 2. Identification of alternative $\mathrm{G} \beta_{1} \gamma$ complexes in rod outer segments of $G \gamma_{1}^{-1-}$ and WT mice. A-D, Coimmunoprecipitation experiments were performed by incubating $G \gamma_{1}^{-1-}(\boldsymbol{A}, \boldsymbol{B})$ or WT $(\boldsymbol{C}, \boldsymbol{D})$ rod outer segment lysates with mouse anti-G $\gamma_{2}(\boldsymbol{A}, \boldsymbol{C})$ or rabbit anti-G $\gamma_{3}(\boldsymbol{B}, \boldsymbol{D})$ antibodies. Immunoprecipitation with species-matched anti- $\beta$-actin (sc-47778) and anti-PSMD1 (ab140682) antibodies were used as negative controls; these antibodies were chosen based on the lack of cross-reactivity with the proteins analyzed in this panel, as evaluated in independent experiments. The data represent one of four similar experiments performed with $G \gamma_{1}^{-1-}$ or two similar experiments performed with WT outer segment preparations. 
A

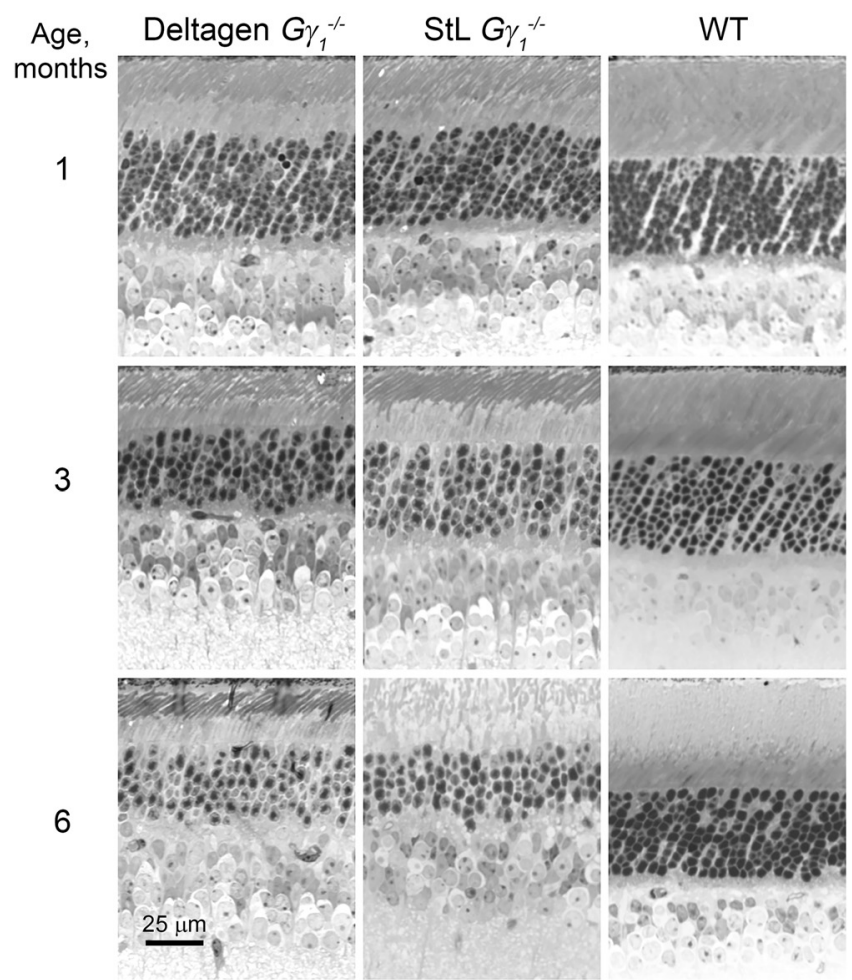

B
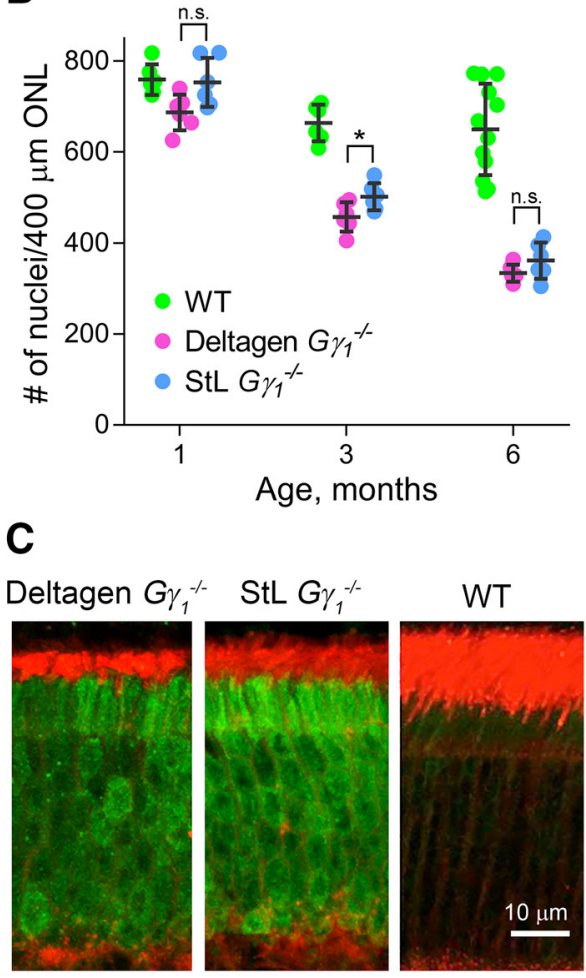

Figure 3. Comparative analysis of retinal morphology in Deltagen and StL $G \gamma_{1}^{-1-}$ mice. $\boldsymbol{A}$, Representative images of toluidine blue-stained, plastic-embedded 1- $\mu \mathrm{m}$-thick retinal cross sections from each mouse strain at the indicated ages. Scale bar, $25 \mu \mathrm{m}$. $\boldsymbol{B}$, The number of photoreceptor nuclei counted in $400 \mu \mathrm{m}$ outer nuclear layer (ONL) segments located $1 \mathrm{~mm}$ from either side of the optic nerve. The number of nuclei in each segment was counted by hand. Data were averaged across nuclear counts obtained from each side of the optic nerve from three or four animals of each age and genotype, and are shown as the mean \pm SD. Each dot represents a single data point. $\boldsymbol{C}$, Accumulation of the Ub G76V_GFP reporter of proteasomal activity (green) in rods of 3-month-old Deltagen and StL $G \gamma_{1}^{-1-}$ mice. A Ub G76V_GFP-expressing WT retina is shown as a control. Wheat germ agglutinin staining is shown in red. Scale bar, $10 \mu \mathrm{m}$.

revealed that, even in the presence of abundant amounts of its cognate partner $\mathrm{G} \gamma_{1}$, a small portion of $\mathrm{G} \beta_{1}$ binds $\mathrm{G} \gamma_{2}$ or $\mathrm{G} \gamma_{3}$. This result suggests that $\mathrm{G} \beta_{1}$ normally forms complexes with these two alternative $\gamma$-subunits in addition to its canonical $\mathrm{G} \gamma_{1}$ binding partner, although these complexes are not likely to be functionally significant due to their low abundance.

Together, our experiments demonstrate that $\mathrm{G} \gamma_{2}$ and $\mathrm{G} \gamma_{3}$ are naturally present in complexes with $\mathrm{G} \beta_{1}$ in the WT rod outer segment. When $G \gamma_{1}$ is knocked out, these alternative $\mathrm{G} \beta_{1} \gamma_{2}$ and $\mathrm{G} \beta_{1} \gamma_{3}$ complexes can support light signaling in mutant photoreceptors.

\section{Evaluation of photoreceptor degeneration in two strains of $G \gamma_{1}^{-/-}$mice}

Another discrepancy reported between the Deltagen and StL $G \gamma_{1}^{-1-}$ mouse strains was that photoreceptor degeneration in the former progressed significantly faster than in the latter. We therefore performed a quantitative side-by-side comparison of the rate of retinal degeneration in these animals. This was accomplished by counting the number of photoreceptor nuclei in representative segments of the ONL at 1, 3, and 6 months of age. Although this method is more labor intensive than commonly used alternatives (e.g., measuring the ONL thickness or count- ing the number of nuclei per ONL stack), it provides the most reliable information on the actual number of photoreceptors remaining "alive" in a degenerating retina. This is because nuclear stacks in degenerating retinas could become distorted and hard to quantify, whereas the ONL thickness may change nonproportionally to the actual cell loss.

Retinas from both $\mathrm{G} \gamma_{1}^{-1-}$ mouse lines were embedded in plastic, cross-sectioned, and stained with toluidine blue (Fig. 3A). Photoreceptor nuclei were then counted in two $400 \mu \mathrm{m}$ segments per eye, one on each side of the optic nerve, and the values were averaged across at least three mice of each age (Fig. 3B). These data indicated that the rates of photoreceptor degeneration in both knock-out strains were nearly identical at all tested ages. Formal analysis suggested that a statistically significant difference in nuclear counts existed in 3-month-old mice $(p=$ $0.065^{\mathrm{c}}$ at 1 month; $p=0.041^{\mathrm{d}}$ at 3 months; $p=0.24^{\mathrm{e}}$ at 6 months). However, the absolute difference of $<10 \%$ is hard to consider physiologically significant. This analysis showed that approximately half of the photoreceptor cells were lost by the age of 6 months, a rate of degeneration that falls somewhere in the middle between the two previous reports. One potential source of this discrepancy is that the first study (Lobanova et al., 2008) did not assess 
this parameter quantitatively and apparently provided more dramatic examples of cellular loss than average. On the other hand, the rate of photoreceptor degeneration in the study by Kolesnikov et al. (2011) may have been underestimated due to the use of the nuclear stack counting methodology, which may be more arbitrary than the total nuclear count.

\section{Photoreceptors from both strains of $G \gamma_{1}^{-1-}$ mice experience proteostatic stress}

Using the Deltagen strain, Lobanova et al. (2013) showed that photoreceptor cell death in $G \gamma_{1}^{-1-}$ mice is associated with proteostatic stress arising from the necessity to degrade large amounts of $\mathrm{G} \beta_{1}$ that is unable to fold without its constitutive $G \gamma_{1}$ partner. We now demonstrate that the same is true for the StL strain. StL mice were crossed with the mouse ubiquitously expressing the $\mathrm{Ub}^{\mathrm{G} 76 \mathrm{~V}}$-GFP proteasome activity reporter, which consists of GFP fused to an uncleavable ubiquitin (Lindsten et al., 2003). This reporter undergoes efficient polyubiquitination and proteasomal degradation in healthy cells, including WT photoreceptors, but accumulates in cells suffering from impairment or insufficiency of the ubiquitin-proteasome system. Consistent with the phenotype of the Deltagen strain, photoreceptors of StL mice also displayed robust intracellular accumulation of Ub ${ }^{\mathrm{G} 76 \mathrm{~V}}$-GFP, as documented by detecting GFP fluorescence in retinal cross sections (Fig. $3 C$ ). This result indicates that both mouse strains suffer from abnormal proteostasis, contributing to their photoreceptor degeneration.

\section{Discussion}

The data presented in this study demonstrate that the two lines of $\mathrm{G} \gamma_{1}$ knock-out mice currently available to the scientific community display essentially identical phenotypes. Not only do they produce similar responses to light, as reported earlier, but they also contain identical amounts of $\mathrm{G} \alpha_{\mathrm{t}}$ and $\mathrm{G} \beta_{1}$ subunits in their rods, undergo retinal degeneration at a similar rate, and share the same underlying pathobiological mechanism. Therefore, these strains could be used interchangeably in future studies of this mouse model.

Most importantly, resolving the discrepancy between previous estimates of the contents of transducin subunits in these strains allowed us to explain the mechanism by which photoreceptors respond to light in the absence of the transducin canonical $\beta \gamma$-subunit $G \beta_{1} \gamma_{1}$. Here we demonstrate that relatively small amounts of $G \gamma_{2}$ and $G \gamma_{3}$ are endogenously expressed in the outer segments of these cells where they produce complexes with $G \beta_{1}$. These complexes are able to support vision in the absence of the $\mathrm{G} \beta_{1}$ cognate $\gamma$-subunit $\mathrm{G} \gamma_{1}$.

Our findings highlight the versatility of G-protein signaling by showing the exchangeability of individual G-protein subunits in performing an important physiologic function. Mouse and human genomes contain genes encoding 5 G-protein $\beta$-subunits and $14 \gamma$-subunits (Milligan and Kostenis, 2006), and their expression patterns in different tissues vary widely (Largent et al., 1988; Gautam et al., 1990; Cali et al., 1992; Liang et al., 1998; Morishita et al., 1998). Given that many possible $\mathrm{G} \beta \gamma$ combinations exist, a key question in G-protein signaling is whether heterotrimers composed of distinct subunits can fulfill the same physiologic role. Many examples documented in cell culture and in vitro show that $\mathrm{G} \beta \gamma$ complexes using different $\gamma$-subunits are able to activate the same signaling cascades (Wickman et al., 1994; Ikeda, 1996; Ruiz-Velaso and Ikeda, 2000). This includes at least three cell culture studies specifically demonstrating the functional interchangeability of $\mathrm{G} \beta_{1} \gamma_{1}, \mathrm{G} \beta_{1} \gamma_{2}$, and $\mathrm{G} \beta_{1} \gamma_{3}$ (Hawes et al., 1995; Dingus et al., 2005; Poon et al., 2009).

Examination of $\gamma$-subunit exchangeability in the context of the whole animal has thus far been limited, but results obtained in several mouse knock-out studies have suggested that there may be a more stringent requirement for $\gamma$-subunit specificity in vivo than in cell culture. For example, $\mathbf{G} \gamma_{7}$ is indispensable for adenylyl cyclase signaling through the $A_{2 A}$ receptor in the striatum (Schwindinger et al., 2003, 2010), whereas $\mathrm{G} \gamma_{13}$ is required for olfactory signal transduction (Li et al., 2013).

We now provide a compelling example of the functional interchangeability of G-protein $\gamma$-subunits in vivo. To our knowledge, $G \gamma_{1}^{-1-}$ represents the first case to directly demonstrate that multiple $\mathrm{G} \beta \gamma$ complexes can perform the same function in a living animal. The only caveat is that the expression levels of alternative $\gamma$-subunits in photoreceptors are lower than those of the conventional $\mathrm{G} \gamma_{1}$ and, therefore, the $\mathrm{G} \beta_{1} \gamma_{1}$ complex drives the majority of phototransduction unless $\mathrm{G} \gamma_{1}$ is absent.

\section{References}

Arshavsky VY, Burns ME (2012) Photoreceptor signaling: supporting vision across a wide range of light intensities. J Biol Chem 287: 1620-1626. CrossRef Medline

Arshavsky VY, Burns ME (2014) Current understanding of signal amplification in phototransduction. Cell Logist 4:e29390. CrossRef Cali JJ, Balcueva EA, Rybalkin I, Robishaw JD (1992) Selective tissue distribution of $\mathrm{G}$ protein $\gamma$ subunits, including a new form of the $\gamma$ subunits identified by cDNA cloning. J Biol Chem 267:2402324027. Medline

Calvert PD, Krasnoperova NV, Lyubarsky AL, Isayama T, Nicoló M, Kosaras B, Wong G, Gannon KS, Margolskee RF, Sidman RL, Pugh EN Jr, Makino CL, Lem J (2000) Phototransduction in transgenic mice after targeted deletion of the rod transducin $\alpha$-subunit. Proc Natl Acad Sci U S A 97:13913-13918. CrossRef

Dingus J, Wells CA, Campbell L, Cleator JH, Robinson K, Hildebrandt JD (2005) G protein betagamma dimer formation: Gbeta and Ggamma differentially determine efficiency of in vitro dimer formation. Biochemistry 44:11882-11890. CrossRef Medline

Fung BK (1983) Characterization of transducin from bovine retinal rod outer segments. I. Separation and reconstitution of the subunits. J Biol Chem 258:10495-10502. Medline

Gautam N, Northup J, Tamir H, Simon MI (1990) G protein diversity is increased by associations with a variety of $\gamma$ subunits. Proc Natl Acad Sci U S A 87:7973-7977. Medline

Hawes BE, van Biesen T, Koch WJ, Luttrell LM, Lefkowitz RJ (1995) Distinct pathways of Gi- and Gq-mediated mitogen-activated protein kinase activation. J Biol Chem 270:17148-17153. Medline

Heck M, Hofmann KP (2001) Maximal rate and nucleotide dependence of rhodopsin-catalyzed transducin activation: initial rate analysis based on a double displacement mechanism. J Biol Chem 276:10000-10009. CrossRef Medline

Herrmann R, Heck M, Henklein P, Hofmann KP, Ernst OP (2006) Signal transfer from GPCRs to $G$ proteins: role of the $G$ alpha $\mathrm{N}$-terminal region in rhodopsin-transducin coupling. J Biol Chem 281:30234-30241. CrossRef 
Ikeda SR (1996) Voltage-dependent modulation of N-type calcium channels by G-protein $\beta \gamma$ subunits. Nature 380:255-258. CrossRef

Kisselev OG, Meyer CK, Heck M, Ernst OP, Hofmann KP (1999) Signal transfer from rhodopsin to the G-protein: evidence for a two-site sequential fit mechanism. Proc Natl Acad Sci U S A 96:4898-4903. Medline

Kolesnikov AV, Rikimaru L, Hennig AK, Lukasiewicz PD, Fliesler SJ, Govardovskii VI, Kefalov VJ, Kisselev OG (2011) G-protein $\beta \gamma$ complex is crucial for efficient signal amplification in vision. $J$ Neurosci 31:8067-8077. CrossRef Medline

Largent BL, Jones DT, Reed RR, Pearson RC, Snyder SH (1988) G protein $\mathrm{mRNA}$ mapped in rat brain by in situ hybridization. Proc Natl Acad Sci U S A 85:2864-2868. Medline

Li F, Ponissery-Saidu S, Yee KK, Wang H, Chen M-L, Iguchi N, Zhang G, Jiang P, Reisert J, Huang L (2013) Heterotrimeric G protein subunit $\mathrm{G} \gamma 13$ is critical to olfaction. J Neurosci 33:79757984. CrossRef Medline

Liang J-J, Cockett M, Khawaja XZ (1998) Immunohistochemical localization of $\mathrm{G}$ protein beta1, beta2, beta3, beta4, beta5, and gamma3 subunits in the adult rat brain. J Neurochem 71:345-355. CrossRef

Lindsten K, Menéndez-Benito V, Masucci MG, Dantuma NP (2003) A transgenic mouse model of the ubiquitin/proteasome system. Nat Biotechnol 21:897-902. CrossRef Medline

Lobanova ES, Finkelstein S, Herrmann R, Chen YM, Kessler C, Michaud NA, Trieu LH, Strissel KJ, Burns ME, Arshavsky VY (2008) Transducin $\gamma$-subunit sets expression levels of $\alpha$ - and $\beta$-subunits and is crucial for rod viability. J Neurosci $28: 3510-3520$. CrossRef Medline

Lobanova ES, Herrmann R, Finkelstein S, Reidel B, Skiba NP, Deng WT, Jo R, Weiss ER, Hauswirth WW, Arshavsky VY (2010) Mechanistic basis for the failure of cone transducin to translocate: why cones are never blinded by light. J Neurosci 30:6815-6824. CrossRef

Lobanova ES, Finkelstein S, Skiba NP, Arshavsky VY (2013) Proteasome overload is a common stress factor in multiple forms of inherited retinal degeneration. Proc Natl Acad Sci U S A 110:99869991. CrossRef Medline

Milligan G, Kostenis E (2006) Heterotrimeric G-proteins: a short history. Br J Pharmacol 147 [Suppl 1]:S46-S55. CrossRef

Morishita R, Ueda H, Kato K, Asano T (1998) Identification of two forms of the $\gamma$ subunit of $\mathrm{G}$ protein, gamma10 and gamma11, in bovine lung and their tissue distribution in the rat. FEBS Lett 428:85-88. Medline

Pearring JN, Spencer WJ, Lieu EC, Arshavsky VY (2015) Guanylate cyclase 1 relies on rhodopsin for intracellular stability and ciliary trafficking. Elife 4:e12058. CrossRef

Poon LS, Chan AS, Wong YH (2009) Gbeta3 forms distinct dimers with specific Ggamma subunits and preferentially activates the beta3 isoform of phospholipase C. Cell Signal 21:737-744. CrossRef Medline

Pugh EN Jr, Lamb TD (1993) Amplification and kinetics of the activation steps in phototransduction. Biochim Biophys Acta 1141: 111-149. Medline

V Ruiz-Velasco, S R Ikeda, (2000) Multiple G-protein $\beta \gamma$ combinations produce voltage-dependent inhibition of $\mathrm{N}$-type calcium channels in rat superior cervical ganglion neurons. J Neurosci 20:2183-2191. Medline

Schwindinger WF, Betz KS, Giger KE, Sabol A, Bronson SK, Robishaw JD (2003) Loss of G protein gamma7 alters behavior and reduces striatal alphaolf level and cAMP production. $J$ Biol Chem 278:6575-6579. CrossRef

Schwindinger WF, Mihalcik LJ, Giger KE, Betz KS, Stauffer AM, Linden J, Herve D, Robishaw JD (2010) Adenosine A2A receptor signaling and Golf assembly show a specific requirement for the gamma7 subtype in the striatum. J Biol Chem 285:29787-29796. CrossRef Medline

Sokolov M, Lyubarsky AL, Strissel KJ, Savchenko AB, Govardovski VI, Pugh EN Jr, Arshavsky VY (2002) Massive light-driven translocation of transducin between the two major compartments of rod cells: a novel mechanism of light adaptation. Neuron 34:95-106. CrossRef

Sokolov M, Strissel KJ, Leskov IB, Michaud NA, Govardovskii VI, Arshavsky VY (2004) Phosducin facilitates light-driven transducin translocation in rod photoreceptors: evidence from the phosducin knockout mouse. J Biol Chem 279:19149-19156. CrossRef Medline

Tsang SH, Burns ME, Calvert PD, Gouras P, Baylor DA, Goff SP, Arshavsky VY (1998) Role for the target enzyme in deactivation of photoreceptor G protein in vivo. Science 282:117-121. Medline

Kevin D. Wickman, Jorge A. Iñiguez-Lluhi, Philip A. Davenport, Ronald Taussig, Grigory B. Krapivinsky, Maurine E. Linder, Alfred G. Gilman, David E. Clapham, (1994) Recombinant G-protein beta gamma-subunits activate the muscarinic-gated atrial potassium channel. Nature 368:255-257. CrossRef 